\title{
Uniform format for disclosure of competing interests in ICMJE journals
}

Previously published at www.cmaj.ca

$\mathrm{D}$ isclosure of financial associations of authors of articles published in biomedical journals has become common practice. The information provided in these disclosures helps the reader to understand the relationships between the authors and various commercial entities that may have an interest in the information reported in the published article. At present, many journals ask authors to report such relationships by completing a form with information about their financial associations. The journals then either post the complete information online or create a summary of the information and publish it with the article in question. Although efforts are under way to establish uniform reporting systems, there is currently no uniform vehicle for the disclosure of financial associations. Thus, authors may provide similar information to different journals in multiple formats. In addition, slight differences among journals in requirements for reporting can lead to confusion, as the same individual may report different information to different journals. With this editorial, which is being published simultaneously in all International Committee of Medical Journal Editors (ICMJE) journals, we introduce a new disclosure form that has been adopted by all journals that are members of the ICMJE. We encourage other journals to adopt this reporting format, and we are placing the form in the public domain.

We ask authors to disclose four types of information: (1) their associations with commercial entities that provided support for the work reported in the submitted manuscript (the time frame for disclosure in this section of the form is the lifespan of the work being reported); (2) their associations with commercial entities that could be viewed as having an interest in the general area of the submitted manuscript (the time frame for disclosure in this section is the 36 months before submission of the manuscript); (3) any similar financial associations involving their spouse or their children under 18 years of age; and (4) nonfinancial associations that may be relevant to the submitted manuscript.

The form, now posted on the ICMJE website and at cmaj.ca (Appendix 1, available at www.cmaj.ca/cgi/content/full/cmaj .091691/DC1), includes instructions to help authors provide the information. Authors can download the form from the Internet, add the requested information and save the completed form on their computer. The completed form can then be uploaded through the electronic manuscript submission system of the journal that has requested the information. Since all ICMJE journals now use the same reporting format, authors may save a partially completed form on their computers. When a manuscript is ready for submission to a journal that accepts this reporting format, authors can simply finish completing the form by adding information specific to the manuscript and then upload the completed form to the journal's manuscript submission system. Our goal is to make the process of disclosure uniform and easy; the new form should eliminate the need to reformat disclosure information for specific journals.

We realize this disclosure form requires authors to report a great deal of information about their relationships with entities that could be viewed as having interests that compete with the research being reported. With this in mind, some journals may ask for all of these details at the time of initial manuscript submission, whereas other journals may ask for much less information at submission and require completion of the detailed form later in the editorial process. These decisions will be left to the discretion of the journal.

We also realize that to be useful, the reporting format must be responsive to community needs. Although ICMJE member journals have "use-tested" the form, there may be situations that are not covered by the form, aspects of the instructions that are unclear, or bugs in the programming that we have not yet discovered. Therefore, we regard the period from publication of this editorial until Apr. 10, 2010, as a period of $\beta$-testing. We encourage you to let us know about problems that arise with the form and to send us your comments by using the comments feature on the home page of the ICMJE website (www.icmje.org). The ICMJE will meet in late April 2010 and will adapt the form to address concerns identified by users. In the future, we will revisit the form's usefulness and modify it as needed. We are grateful to the authors who take the time to provide complete disclosure information and thus help to ensure the transparency of the publication process. By adopting a uniform format, we hope to make the process of disclosure of competing interests easier for authors and less confusing for readers.

\section{Jeffrey M. Drazen MD}

Editor-in-Chief, New England Journal of Medicine

Martin B. Van Der Weyden MD

Editor, The Medical Journal of Australia

Peush Sahni MS PhD

Representative and Past President, World Association of Medical Editors Jacob Rosenberg MD DSc

Editor, Journal of the Danish Medical Association

Ana Marusic MD PhD

Editor-in-Chief, Croatian Medical Journal

Christine Laine MD MPH

Editor, Annals of Internal Medicine

Sheldon Kotzin MLS

Associate Director for Library Operations, National Library of Medicine Richard Horton FMed Sci

Editor, The Lancet

Paul C. Hébert MD MHSc

Editor-in-Chief, Canadian Medical Association Journal

Charlotte Haug MD PhD MSc

Editor-in-Chief, Norwegian Medical Journal

Fiona Godlee MB BChir BSc

Editor-in-Chief, $B M J$

Frank A. Frizelle MB ChB

Editor-in-Chief, The New Zealand Medical Journal

Peter W. de Leeuw MD PhD

Editor-in-Chief, Nederlands Tijdschrift voor Geneeskunde

(Dutch Journal of Medicine)

Catherine D. DeAngelis MD MPH

Editor-in-Chief, JAMA

\section{Competing interests: None declared.}

Cite as CMAJ 2009. DOI:10.1503/cmaj.091691

Editor's note: This editorial is being published simultaneously in all ICMJE member journals.

Disclaimer: Dr. Sahni's affiliation as representative and past president of the World Association of Medical Editors (WAME) does not imply endorsement by WAME member journals that are not part of the ICMJE.

All editorial matter in CMAJ represents the opinions of the authors and not necessarily those of the Canadian Medical Association. 